nucleus accumbens, consisting of down-regulation of dopamine receptors in the mesostriatum and hypothalamus. Such a response might result in a reduction in local dopaminergic tone sufficient to produce lethal catatonia, despite mesolimbic hyperdopaminergia simultaneously producing psychosis.

In spite of the great attention these two possibly related entities have received of late, we still known remarkably little about the pathophysiology of either.

AYD, F. J. (1956) Fatal hyperpyrexia during chlorpromazine therapy. Journal of Clinical Psychiatry, 27, 189-192.

Friccione, G. L. (1985) Neuroleptic catatonia and its relationship to psychogenic catatonia. Biological Psychiatry, 20, 304-313.

FrIEDHOFF, A. J. (1983) A strategy for developing novel drugs for the treatment of schizophrenia. Schizophrenia Bulletin, 9, 555-562.

LINDESAY, J. (1986) Neuroleptic malignant syndrome and lethal catatonia. British Journal of Psychiatry, 148, 342-343.

Redlich, F. C. \& Frifdman, D. X. (1966) The Theory and Practice of Psychiatry. New York: Basic Books.

Yale University School of Medicine

J.G. LONGHURST

611 Grace Education Building

25 Park Street

New Haven

Connecticut 06519

\section{Predictors of psychiatric morbidity in cancer patients}

SIR: Harrison \& Maguire's enjoyable review (BJP, November 1994, 165, 593-598) referred to the work of myself and colleagues (Hughson et al, 1986) showing that chemotherapy increased psychological morbidity after mastectomy; they state also that this paper showed that the psychological consequences of radiotherapy after mastectomy persisted beyond six months.

I have never thought that this paper demonstrated persisting psychological morbidity due to radiotherapy. While it compared chemotherapy with radiotherapy, it did not contain a comparison with patients receiving no further treatment after mastectomy. Hence it could not distinguish between the effects of radiotherapy and the effects of having a mastectomy for cancer. However, in a subsequent paper (Hughson et al, 1987) we did compare patients having radiotherapy after mastectomy with those receiving no further treatment. Somewhat to our surprise, we failed to demonstrate any significant excess of anxiety or depression in the patients treated with radiotherapy, although they did show a significant excess of somatic symptoms and social dysfunction.
Despite this negative result, having interviewed all the patients personally, I am in no doubt that a few of them experienced anxiety or even panic caused by going under the radiotherapy machine. But I think that this anxiety was offset by the reassurance other patients got from getting further treatment and from having regular contact with the radiotherapy staff. The control patients having no further treatment after mastectomy had little contact with staff and hence less opportunity to be reassured. The psychological effects of having radiotherapy are more subtle than first appears, perhaps also varying with dosage (our patients did not receive very high doses), and I agree entirely with Drs Harrison and Maguire that further work is needed to look at the effects of radiotherapy for specific disease groups.

Hughson, A. V. M., CoOper, A. F., MCArdle, C. S., et al (1986) Psychological impact of adjuvant chemotherapy in the first two years after mastectomy. British Medical Journal, 293, 1268-1271.

-, -, - et al (1987) Psychosocial effects of radiotherapy after mastectomy. British Medical Journal, 294, 1515-1518.

Leverndale Hospital

A.V.M. HughSON

510 Crookston Road

Glasgow G53 7TU

\section{Worcester Development Project and Powick Hospital}

SIR: Those who worked at Powick Hospital, Worcester (including at least one ex-President of the Royal College), those who took an interest in the Worcester Development Project, and those who happened to read Ian Brockington's and my own book (1991), may be interested to know that the Worcester Development Project story has now finally ended.

It began with the proposition in 1970 that the then DHSS would close a single large mental hospital and replace it with a diverse range of psychiatric facilities in the community as a model national project. The eventual sale of the old mental hospital site would repay the original pump-priming capital invested.

Due to the insistence of all the mental health professionals involved (academic, DHSS and local) the old mental hospital was not closed until the new day hospitals, acute in-patient unit, hostels, etc. had been up and running for some time. The result of that foresight is that - unlike less fortunate areas the citizens of south and mid-Worcestershire have had a viable and modern community-based 
psychiatric service since 1979, the old hospital finally closing completely in 1989 . Some might find it remarkable that in all the heat currently generated by protagonists and antagonists of community psychiatry, the small but significant amount of light shed by the Worcester Development Project never seems to be mentioned ...

As one of those who is rather proud to 'have been there and done that' I feel that it is worth recording that the hospital site has finally (due to the state of the housing market) been sold to Bovis Homes. The old institution has now been completely demolished apart from the two original houses ("Bredon House" and "White Chimneys") where it all started on 11 August 1852, and a large modern housing development is under construction.

Hall, P. \& Brockington, I. F. (1991) The Closure of Mental Hospitals. London: The Royal College of Psychiatrists (Gaskell).

"Leafield"

P. HALL

\section{Ryall Lane}

Upton-upon-Severn

Worcs. WR8 OPN

\section{Efiectiveness and eficiency in psychiatry}

SIR: We read Shanks' reconsideration of Cochrane's Effectiveness and Efficiency with interest and pleasure (BJP, November 1994, 165, 702-704). Shanks may well be correct in suggesting that psychiatry would be further down the road to knowledge-based health care if Cochrane had given us "a more decisive raspberry" when distributing awards for specialities acting with least regard to the best research evidence.

Psychiatry's response to Cochrane's challenge has been tardy but is beginning to take shape. In January 1994, at the Winter Workshop on Schizophrenia (Switzerland), the Cochrane Schizophrenia Group was formed (Cochrane Collaboration Schizophrenia Group, 1994). This now consists of an international group of reviewers, editors and an administrator. Already, as a result of methodical electronic and manual searching, a register of RCTs relevant to schizophrenia exists. In early October 1994 Dr Jair Mari (Sao Paulo, Brazil) put a systematically conducted review (family intervention for schizophrenia) into electronic form. This substantially updates a previous publication that came into print in August 1994 (Mari \& Steiner, 1994). This electronic review is included in the prototype of the Cochrane Database of Systematic Reviews. The prototype is now being tested and refined, and will be issued in March 1995 and updated every six months from then on.

Other sub-specialities within mental health have also expressed interest and invested effort. Groups focusing on the affective disorders, child psychiatry, learning disabilities, OCD and psychological medicine are in their early stages.

Certainly compiling and disseminating the best available evidence of the effectiveness and efficiency of care is one thing and getting it into practice is another. Initiatives such as teaching students and postgraduates evidence-based practice (EvidenceBased Medicine Working Group, 1992), the Getting Research into Practice and Purchasing (GRiPP) project for clinicians and managers (Dunning et al, 1994), changing examination procedures to include critical appraisal of research literature (Moore, 1994), and dissemination of evidence to the 'consumers' of care (Enkin et al, 1994) must help.

Cochrane's challenge has set in motion even psychiatry and the speciality is making steady progress towards a more knowledge-based mental health service. Anyone interested in this project, especially those willing to invest effort, are welcome to contact either author.

Cochrane Collaboration Schizophrenu Review Group (1994) Schizophrenia and the Cochrane Collaboration. Schizophrenia Research, 13, 185-188.

DUNNING, M., MCQUAY, H. \& MnNE, R. (1994) Getting a grip. Health Service Journal, 4, 24-25.

ENTIN, M., KeIRSE, M. J. N. C., Renfrew, M. J., el al (1994) Guide to Effective Care in Pregnancy and Childbirth. 2nd edn. Oxford: Oxford University Press.

Evidence-Based Medicine Workng Group (1992) Evidencebased medicine: a new approach to teaching the practice of medicine. Journal of the American Medical Association, 268, 2420-2425

MARI, J. \& STEINER, D. (1994) An overview of family interventions and relapse on schizophrenia: meta-analysis of research findings. Psychological Medicine, 23, 565-578.

MoORE, R. (1994) The MRCGP examination: a guide for candidates and teachers. London: Royal College of General Practitioners.

S. Wessel Y

Mental Health Coordinator for the Cochrane Collaboration

Academic Dept of Psychological Medicine

King's College School of Medicine

103 Denmark Hill

London SE5 $8 A Z$

\section{Coordinating editor}

The Cochrane Schizophrenia Group

Institute of Health Sciences

PO Box 777, Oxford OX3 7JX

E-mail: ceadams@vax.ox.ac.uk 